\title{
Histologia dos sacos herniários nas hérnias inguinais em adultos e crianças: presença de fibras musculares lisas e sua relação com o vaso sanguíneo
}

\author{
Hernial sac hystology of the inguinal hernias: identification of smooth muscle \\ fibers and their relation with the blood vessel
}

Artur Laizo' ACbC-MG ${ }^{1}$; Rafael Silveira Vasconcelos ${ }^{2}$; Ângela Maria Gollner ${ }^{3}$; Alcino Lázaro da Silva, ECBC - MG ${ }^{4}$

RE S U M O

\begin{abstract}
Objetivo: Estudar a relação dos vasos sanguíneos e as fibras de músculo liso presentes no saco herniário. Métodos: Foram realizadas 250 operações para correção de hérnia inguinal em crianças e adultos de dois meses a 75 anos, no período de julho de 2002 a fevereiro de 2003. Foram isolados 192 sacos herniários em 184 procedimentos e somente oito pacientes foram tratados com hérnia inguinal bilateral. Foram excluídos os pacientes que não apresentavam saco herniário durante as operações, e nas mulheres por não haver material. Destes 184 casos, foram escolhidos, aleatoriamente, 90 pacientes para realização desta análise distribuídos em três grupos: 30 adultos masculinos, 30 crianças do gênero feminino e 30 crianças do gênero masculino. Resultados: Os vasos sanguíneos estavam presentes em todos os campos estudados com uma média de 11 vasos por campo. As fibras de músculo liso estavam presentes em alguns casos e tanto na distância horizontal quanto na vertical com a arteríola escolhida, não apresentavam nenhuma relação. Conclusão: As fibras de músculo liso são próprias do saco herniário e não relacionadas com as dos vasos sanguíneos.
\end{abstract}

Descritores: Hérnia inguinal. Histologia. Músculo liso. Fibras musculares.

\section{INTRODUÇÃO}

A hérnia inguinal sempre será motivo de estudo e aperfeiçoamento de técnicas cirúrgicas. Estima-se que $10 \%$ das operações de hérnias realizadas por ano destinam-se à correção das recidivadas. Cerca de 40 a 50\% das recidivas ocorrem no primeiro ano de pós-operatório, o que se associa a deficiência técnica ou do método de correção'.

No tratamento cirúrgico da hérnia inguinal, durante séculos, houve numerosas tentativas de reforço até a contemporaneidade, quando surgiram as próteses sintéticas. Elas oferecem esse benefício, mas são corpos estranhos e como tal, vez por outra, criam problemas de rejeição e extrusão².

Tentando compatibilizar a necessidade de não se ter rejeição - comum às próteses sintética, e produzir reforço satisfatório, passou-se, nas últimas décadas, a se fazerem ensaios e depois pesquisas sobre o uso do saco herniário analógeno. Nessa linha de trabalhos, constatouse histologicamente no saco herniário a presença de fibras de musculatura lisa que, como se sabe, não pode se origi- nar de contaminação por parte da musculatura lisa abdominal. A origem não está ainda identificada. Seria por diferenciação celular? Por célula-tronco? Originada do endotélio vascular? Migrada de musculatura lisa no processo de descida testicular? São numerosas as perguntas que respondidas com acerto podem levar ao conhecimento próximo da fisiopatologia herniária.

Desenvolveram-se, por exemplo, vários materiais para reforço da parede abdominal na operação corretiva da hérnia no adulto, como telas artificiais, e há estudos utilizando o próprio saco herniário para reforço dessa região ${ }^{1,3}$.

Durante muito tempo desprezado ${ }^{4}$, esse saco peritoneal produzido pela saída dos órgãos do interior do abdome é motivo de estudo, visando a demonstrar as estruturas presentes e, principalmente, a vasculatura e sua relação com os músculos lisos ${ }^{5-7}$.

O objetivo deste trabalho é fazer o estudo histológico e verificar a distância entre as fibras musculares lisas e o componente vascular presente no saco herniário de hérnias inguinais diretas, indiretas e recidivadas nas diversas faixas etárias e em ambos os sexos.

Trabalho realizado no Programa de Pós-Graduação em Cirurgia da Universidade Federal de Minas Gerais e no Hospital Municipal Dr. Mozart Geraldo Teixeira em Juiz de Fora, MG - BR.

1. Mestre em Cirurgia pela Faculdade de Medicina da Universidade Federal de Minas Gerais, Belo Horizonte, MG - BR; 2. Fisioterapeuta pela Universidade Presidente Antônio Carlos - UNIPAC, Juiz de Fora, MG - BR; 3. Professora Adjunta da Universidade Federal de Juiz de Fora, MG BR; 4. Professor Emérito da Universidade Federal de Minas Gerais, Belo Horizonte, MG - BR. 


\section{MÉTODOS}

O trabalho foi aprovado pelo Comitê de Ética e Pesquisa da Universidade Federal de Juiz de Fora, e aprovada a colheita de dados e realização da pesquisa.

Os pacientes foram operados no Hospital Municipal Dr. Mozart Geraldo Teixeira de Juiz de Fora. Foram realizadas 250 operações para correção de hérnia inguinal direta, indireta e recidivante em crianças de dois meses a 12 anos e adultos acima de 12 anos a 75 anos de idade, no período de julho de 2002 a fevereiro de 2003 e os espécimes herniários enviados para análise histológica.

Os sacos das hérnias indiretas foram retirados em sua totalidade. Nas diretas, em função da técnica operatória, optou-se pela retirada de parte da cúpula do saco. As amostras foram retiradas e enviadas para estudo anatomopatológico, fixadas em formalina a 10\%, procedendo-se ao estudo histopatológico pelas colorações Hematoxilina-Eosina e Gomori.

Foram excluídos do estudo os pacientes que não apresentavam saco herniário durante o ato operatório devido à anatomia ou tipo da hérnia.

Dos 184 pacientes dos quais obtive-se saco herniário, foram escolhidos aleatoriamente, para realização do estudo, 90 pacientes distribuídos da seguinte forma: 30 crianças do gênero masculino, 30 crianças do gênero feminino e 30 adultos do gênero masculino. Foi medida a distância entre ilhas musculares a uma artéria escolhida em razão de seu tamanho. Procurou-se, em cada amostra, uma artéria de calibre semelhante que foi centralizada no campo, e procedeu-se, então, à contagem do número de vasos presentes e o número de ilhas de histologicamente. Mediu-se a distância entre esta artéria e as ilhas isoladas de fibras de musculatura lisa, e não se encontrou relação entre elas na maioria dos casos.
Na análise estatística, optou-se pelos métodos de Sperman e Pearson devido aos dados não apresentarem distribuição simétrica.

\section{RESULTADOS}

A presença de vasos sanguíneos nas amostras foi significativa: no grupo adulto, encontraram-se vasos em todos os campos, com uma média de 11 por campo; no grupo criança masculino, 10,5; no grupo criança feminino, 10,8 .

Nos casos onde se evidenciaram fibras de musculatura lisa no grupo adulto, a distância horizontal do vaso escolhido à ilha de fibras de musculatura lisa foi em média $0,1665 \mu$ e a distância vertical $0,1378 \mu$, o número de ilhas dessas fibras foi em média 4,5 por campo e o número de vasos 10,83 .

No grupo criança masculino, a distância horizontal do vaso escolhido à ilha de fibras de musculatura lisa foi de $0,135 \mu$, a vertical $0,190 \mu$, o número de ilhas por campo foi em média 5,35 e o número de vasos em média 10,5.

No grupo criança feminino, a distância horizontal foi de $0,052 \mu$, a distância vertical $0,037 \mu$, o número de vasos 10,8 e a média de ilhas de 4,75.

À análise estatística, nota-se que algumas correlações foram significantes $(p<0,05)$ e outras não. Mas todas apontam na mesma direção, de uma correlação positiva, isto é, à medida que aumenta a distância ao vaso, tende a aumentar a quantidade de ilhas. O coeficiente de correlação de Spearman foi mais sensível neste caso devido ao fato de que estas variáveis não têm uma distribuição normal (Tabelas 1 e 2).

Tabela 1 - Correlação entre a quantidade de ilhas de fibras de musculatura lisa e o número de vasos no campo.

\begin{tabular}{lccc}
\hline & Adulto & Criança feminina & Criança masculina \\
\hline Correlação de Paerson & $-0,33$ & $-0,24$ & $-0,17$ \\
Correlaçao de Sperman & $-0,12$ & $-0,46$ & $-0,12$ \\
\hline
\end{tabular}

Tabela 2 - Correlação entre a quantidade de ilhas de fibras de musculatura lisa e a distância horizontal e vertical.

\begin{tabular}{lccc}
\hline & Adulto & $\begin{array}{c}\text { Criança } \\
\text { feminina }\end{array}$ & $\begin{array}{c}\text { Criança } \\
\text { masculina }\end{array}$ \\
\hline Correlação de Paerson entre a quantidade de ilhas e a distância horizontal. & 0,39 & 0,67 & 0,25 \\
& $p=0,034$ & $p=0,000$ & $p=0,185$ \\
Correlaçao de Sperman entre a quantidade de ilhas e a distância horizontal & 0,56 & 0,98 & 0,80 \\
& $p=0,001$ & $p=0,000$ & $p=0,000$ \\
Correlação de Paerson entre a quantidade de ilhas e a distância vertical. & 0,14 & 0,85 & 0,39 \\
& $p=0,474$ & $p=0,000$ & $p=0,051$ \\
Correlaçao de Sperman entre a quantidade de ilhas e a distância vertical. & 0,45 & $0,93 \quad 0,77$ \\
& $p=0,013$ & $p=0,000$ & $p=0,000$ \\
\hline
\end{tabular}




\section{DISCUSSÃO}

O objetivo em demonstrar a relação de distância entre a musculatura lisa e a vasculatura faz parte de uma linha de pesquisa iniciada em 1971 por Lázaro da Silva, a partir do estudo histológico do saco herniário, visando a identificar seus componentes e identificados, desde então, tecido fibroso ${ }^{3}$, tecido conjuntivo frouxo e denso, fibras colágenas tipo I e II (reticulares e elásticas), tecido adiposo, fibroblastos, miofibroblastos, mesotélio e músculo liso ${ }^{7,9-11}$.

A identificação das fibras de musculatura lisa se deu ao acaso e, sendo um achado novo, não relatado na literatura, suscitou indagações que vêm sendo respondidas ao longo dos diversos estudos que compõem essa pesqui$\mathrm{sa}^{12}$

Tanyel ${ }^{13}$ fez hipóteses sobre a função dessas fibras no tecido, sugerindo o aumento da resistência do saco herniário, já que ele apresenta pouca elasticidade. Qual a origem das fibras de musculatura lisa foi outra dúvida. Seriam elas dependentes da musculatura do vaso pela proximidade onde se encontram? Como justificar as ilhas de fibras afastadas de vasos ou mesmo grande presença delas em regiões com menor presença de circulação? A origem destes músculos seria por miogênese ou por satelitose muscular originada das fibras de musculatura lisa dos vasos? Pucci14 em 1986 sugere que haja neogênese muscular.

Barbosa em 2000, analisou a presença delas no saco herniário de adultos e crianças e constatou que não havia diferença significativa entre o local da biópsia no saco, ou seja, proximal, medial ou longitudinal ao anel inguinal interno, bem como demonstrou que a diferença entre homens e mulheres e adultos e crianças não tinha importância significativa ${ }^{6}$. Neste estudo, não houve também diferença significativa entre os grupos.

Neste estudo, verificou-se que a maioria das ilhas nos campos estudados é isolada das fibras de musculatura lisa do vaso arterial. Viu-se, ainda, que há campos repletos de vasos sem elas e campos onde tem-se diversas ilhas e poucos vasos. Constatou-se, assim, que ela é própria do saco herniário, independente do vaso.

Surge então, outra dúvida: quem sabe o bom resultado do uso do saco herniário no reforço das hérnias se deva á presença de fibras de musculatura lisa que dá elasticidade e força tênsil ao saco herniário?

Assim, conclui-se que a presença de fibras de musculatura lisa no saco herniário seria própria do tecido peritoneal, independente das dos vasos.

\title{
A B
}

\begin{abstract}
Objective: To study the correlation between the blood vessels and the smooth muscles in the hernial sac. Methods: 250 surgeries were done to correct inguinal hernias, in children and adults from two months to 75 years old, from March 2002 and February 2003. A hundred ninety two hernial sacs were isolated in 184 surgeries and only eight patients were treated of bilateral inguinal hernia. They were excluded the patients with inguinal hernia which did not have hernial sac during the surgeries and the adult women cause there was no material. From these 184 cases, 90 patients were chosen aleatorialy to make this analysis. They were distributed as follows: 30 male children, 30 female children and 30 male adults. Results: The vessels were present in all groups with a media of 11 vessels per field. The smooth muscle fibers were present in some cases and the horizontal distance was in media $0,1665 \mu$ and the vertical $0,1378 \mu$ in the adult group with a media of 4,5 isle of smooth muscle fibers, in the child male group the horizontal distance was $0,135 \mu$, the vertical $0,190 \mu$ and the isle, 5,35. In the child female group, the horizontal distance was $0,052 \mu$, the vertical 0,037 $\mu$ and the median number of isles, 4,75. Conclusion: The majority of smooth muscles fibers would be proper of the hernial sac independent of the smooth muscles fibers of the blood vessels.
\end{abstract}

Key words: Hernia, inguinal. Histology. Muscle, smooth. Muscle fibers.

\section{REFERENCIAS}

1. Silva AL. Hérnias da parede Abdominal. Rio de Janeiro: Atheneu, V. 1, 1997

2. Netto AC. Clínica cirúrgica. $4^{a}$ ed. São Paulo: Sarvier; 1994.

3. Escalante JR, Diogo Filho A, Andrade Jl. Tratamento de hérnias incisionais volumosas pela técnica de Alcino Lázaro da Silva. Rev Col Bras Cir. 1983; 10(1):24-8.

4. Miller GG, McDonald SE, Milbrandt K, Chibbar R. Routine pathological evaluation of tissue from inguinal hernias in children is unnecessary. Can J Surg. 2003; 46(2):117-9.

5. Adriani AC. Avaliação histológica do saco herniário de hérnias inguinais [dissertação]. Florianópolis (SC): Universidade Federal de Santa Catarina; 2000.

6. Barbosa CA. Histopatologia do saco herniário da hérnia inguinal indireta e do peritônio parietal em adultos e crianças, estudo qualitativo da sua musculatura lisa [dissertação]. Belo Horizonte (MG): Universidade Federal Minas Gerais.
7. Barbosa CA, Amaral VF, Lázaro da Silva A. histopatologia do saco herniário da hérnia inguinal indireta e do peritônio parietal em adultos e crianças: estudo qualitativo da sua musculatura. Rev Col Bras Cir. 2000; 27(4):183-8.

8. Lázaro da Silva A. Plástica com saco herniário na correção das hérnias incisionais. Hospital. 1971; 79(1):129-34.

9. Ross MH, Reith EJ, Romrell LJ. Tecido conjuntivo. In: Histologia: texto e atlas. $2^{a}$ ed. São Paulo: Panamericana; 1993. p. 85-115.

10. Faria LP, Lázaro da Silva A, Rocha A. Hérnias incisionais medianas e paramedianas: estudo do saco herniário à microscopia óptica (mesotélio, tecido conjuntivo frouxo e denso com presença de fibras colágenas, reticulares e elásticas). Rev Col Bras Cir. 1996; 23(4):187-91.

11. Lázaro da Silva A, Brasileiro Filho G, Ferreira AP. Patologia do saco herniário. In: Lázaro da Silva A. Hérnias. $1^{\text {a }}$ ed. São Paulo: Roca; 1992. p. 1226-040.

12. Lázaro da Silva A. Pesquisa em hérnia. Rev Col Bras Cir. 1989; 16(4):191. 
13. Tanyel FC, Müftüoglu S, Dagdeviren $A$, Kaymaz FF, Büyükpamukcu $N$. Myofibroblasts defined by electron microscopy suggest the dedifferentiation of smooth muscle within the sac walls associated with congenital inguinal hernia. BJU Int. 2001; 87(3):251-5.

14. Pucci JA. El uso del saco herniário autógeno como refuerzo en la plástica de hérnias inguinales. Cien Med. 1986;1(1):35-42.

Recebido em 23/10/2008

Aceito para publicação em 17/01/2009

Conflito de interesse: nenhum

Fonte de financiamento: nenhuma

\section{Como citar este artigo:}

Laizo A, Vasconcelos RS, Gollner AM, Silva AL. Histologia dos sacos herniários nas hérnias inguinais em adultos e crianças: presença de fibras musculares lisas e sua relação com o vaso sanguíneo. Rev Col Bras Cir. [periódico na Internet] 2009; 36(4). Disponível em URL: http:/ /www.scielo.br/rcbc

\section{Endereço para correspondência:}

Artur Laizo

E-mail: arturangela@nextwave.com.br 